\title{
Appreciative Inquiry: A Tool for Organizational, Programmatic, and Project-Focused Change
}

\author{
Kerry L. Priest \\ Assistant Professor, School of Leadership Studies \\ 103 Leadership Studies Building \\ Kansas State University \\ Manhattan, Kansas 66506 \\ kerryp@k-state.edu \\ Eric K. Kaufman \\ Assistant Professor, Department of Agricultural and Extension Education \\ 2270 Litton Reaves Hall \\ Virginia Tech \\ Blacksburg, Virginia 24061 \\ ekaufman@vt.edu \\ Kelsey Brunton \\ Graduate Assistant, Department of Agricultural and Extension Education \\ 2270 Litton Reaves Hall \\ Virginia Tech \\ Blacksburg, Virginia 24061 \\ church87@vt.edu \\ Megan Seibel \\ Director, Virginia Agriculture Leaders Obtaining Results (VALOR) \\ 2270 Litton Reaves Hall \\ Virginia Tech \\ Blacksburg, Virginia 24061 \\ mseibel@vt.edu
}

\begin{abstract}
This practice paper describes how leadership education faculty and students at Virginia Tech have facilitated change through the use of appreciative inquiry (Ai) at the departmental level, program level, and project level. Appreciative inquiry has been found to be a useful tool for leadership educators, as its foundation in social constructionist philosophy aligns with contemporary leadership and learning theories. This paper outlines (a) the philosophy of $\mathrm{Ai}$ as it applies to organizational development (b) illustrates Ai practices associated with a fivestage model, and (c) highlights three examples that can be used as models for leading change in a variety of organizational situations. The authors suggest that leadership educators are uniquely positioned to serve academic communities as
\end{abstract}


facilitators of change by bridging theory and practice in pursuit of new ways of knowing and working together.

\section{Introduction}

"There is no power for change greater than a community discovering what it cares about." Margaret Wheatley (2002)

Change is often a central focus in the study of leaders and leadership; indeed, dealing with change is a core task of a leader. Kotter (1996) painted a picture of significant change that is happening within organizations and emphasized the role of the leader in the success or failure of transformational change processes. Heifetz, Grashow, and Linsky (2009) described change driven by adaptive challenges - problems that cannot be clearly defined or addressed through known solutions and standard operating procedures. Instead, such challenges often require significant shifts in thinking and practice across the organization. Pink (2006) echoed a societal shift in thinking from logical to conceptual - from specific, task-oriented thinking to inventive, big-picture thinking capabilities. Adaptive leaders are needed to respond to complex change through cultureshaping efforts that help organizations thrive, give people enough challenge to approach change without fear, and to develop leadership capacity (Heifetz et al., 2009). Klein, Rice, and Schermer (2009) emphasized an urgent need for a restorative response to rapid global change, asserting that "the place to begin is with those who exercise the most power, authority, and influence, namely our leaders" (p. 1). Leaders must do more than just respond to and manage change, They must engage and facilitate transformational efforts at multiple organizational levels. At the heart of the Social Change Model (SCM) of leadership is the goal of creating change to benefit the common good (HERI, 1996).

The higher education institution is tasked with multiple missions, including the preparation of leaders who can engage the complex challenges of a changing world. Ayman et al. (2003) suggested that "as our universities stretch beyond traditional academic subjects to focus on leadership, personal growth and development, and even values, higher education is positioned to play a more pivotal role in the development of a leadership culture in our society" (p. 220). Transformative educational practices are needed to "equip learners to engage in dialogue, to see difference as a source of learning... and to engage critically with local or global issues" (Androetti, 2010, p. 245).

Ironically the organizational systems within these institutions are often resistant to transformative change. Leaders in administrative and academic roles can easily fall into patterns of technical problem solving approaches towards adaptive challenges, as opposed to mobilizing new patterns of thinking and working. Strategic planning efforts are common in higher education and often times occur around times of transition in leadership, or in response to program assessment. In 
order to best serve the changing needs of faculty, students, and stakeholders, higher education leaders need strategic planning tools that encourage transformative change. Appreciate inquiry (Ai) has emerged as such a tool, offering not only a set of strategies for planning, but also a guiding philosophy for organizational development.

Appreciate Inquiry is an especially useful tool for leadership educators, as its foundation in social constructionist philosophy aligns with contemporary leadership and learning theories. Leadership educators are uniquely positioned to serve academic communities as facilitators of change by bridging theory and practice in pursuit of new ways of knowing and working together.

The purpose of this paper is to describe how leadership education faculty and students at one university have facilitated change through the use of $\mathrm{Ai}$ at the departmental, program, and project level. Specifically the authors will:

- Describe the philosophy of Ai as it applies to organizational development.

- Describe the Ai practices associated with a five-stage model.

- Highlight three in-process case examples that can be used as models for leading change in a variety of organizational situations.

\section{Background}

Appreciative inquiry emerged in the late 1980s as an iteration of the actionresearch approach to organizational development (Cooperrider \& Srivasa, 1987). Cooperrider and Srivasa suggested that the problem-oriented worldview of traditional action-research methodology limited its generative capacity: that is, the potential ability to help social systems evolve, adapt, and creatively alter patterns over time. Inspired by the potential of uniting theory and practice for the purpose of social change, they proposed that an Ai approach was a more suitable mode of inquiry in a post-industrial society. Appreciate inquiry has evolved into an organizational development approach to change management, understood most commonly as a process-based method that supports organizational transformation (Cooperrider, Whitney, \& Stravos, 2008).

Rooted in social constructionist philosophy, Ai is "more than a method or technique...it is a way of living with, being with, and directly participating in the varieties of social organizations we are compelled to study" (Cooperrider \& Srivasa, 1987, p. 131). The theoretical underpinnings of Ai are expressed through five key principles:

- First is the constructionist principle which emphasizes the connection between social knowledge and organizational destiny (Cooperrider et al., 2008). For leaders to be change agents, they must be able to overcome conventional or habitual ways of thinking, and "unleash the imagination" 
(p. 8) of individuals and groups in order to conceive and construct the future.

- The principle of simultaneity recognizes that "inquiry is intervention" (Cooperrider et al., 2008, p. 9). The process of inquiry is part of the change process itself. They note it is essential for the change agent to articulate questions that set the stage for what is discovered, resulting in stories out of which the future is constructed.

- The poetic principle is a metaphor for understanding human organizations. Thinking of organizations as an "open book" (Cooperrider et al., 2008, p. 9) allows for their stories to continually be co-authored. Therefore, there are endless choices for the focus of inquiry.

- The anticipatory principle suggests that an organization's image of the future is a powerful mobilizing agent of current behavior (Cooperrider et al., 2008). Organizations exist because their leaders share a common discourse or imagination of who they are, how they function, and what they will become. Therefore, this collective imagination is an important resource for generating constructive organizational change.

- Finally, the positive principle suggests that human organizations are affirmative systems - they respond best to positive thought and knowledge (Cooperrider et al., 2008). The momentum for lasting and effective change comes from positive affect through the use of affirmative guiding questions that promote group building.

Together these five principles "clarify that it is the positive image that results in the positive action, [and that] the organization must make the affirmative decision to focus on the positive to lead the inquiry" (Cooperrider et al, 2008, p. 10). The principles provide the necessary foundation for understanding the practice of $\mathrm{Ai}$, as described through a stage-based cycle, referred to as the 5-D model (Donnan, 2005).

The 5-D model is a series of coordinated stages (see Table 1) by which the Ai practitioner guides an organization towards a vision and desired goals centered around a positive core (Cooperrider et al., 2008). Defining the affirmative topic is considered the first step in the Ai process. Critical to this stage is choosing and clarifying the focus of inquiry. This initiates the discovery stage, in which participants identify and appreciate the positive core through sharing life-giving stories. As the organization discovers its potential and higher purpose, it moves into the dream stage, where the participants create a clear, results-oriented vision that enhances the positive core. In the design stage, participants create bold statements of possibility for the ideal organization, creating structures to enact the positive core. The final stage, called the delivery or destiny stage is where implantation happens. In this stage, new ways of thinking and new actions not only increase productivity, efficiency, and performance, but result in organizations that operate with an "appreciative eye" (Cooperrider et al, 2008, p. 47). This process is meant to be ongoing, resulting in new affirmative topics that guide further inquiry. There are a variety of ways that inquiry interventions can be 
structured. It is important to note that 5-D model is a more contemporary version of the model; many sources depict only the four primary stages, beginning with the discovery stage. Stratton-Berkessel (2010) clarified the purpose, task, and deliverables or outcomes of the four primary stages (see Table 1), which can be helpful for practitioners as they navigate the inquiry process.

Table 1

Summary of Ai stage descriptions, purpose, task, and outcomes

\begin{tabular}{|c|c|c|c|}
\hline $\begin{array}{c}\text { Stage and } \\
\text { Key Question }\end{array}$ & Purpose & Task & Outcomes \\
\hline \multicolumn{4}{|l|}{$\begin{array}{l}\text { 1. Defining } \\
\text { "What is the focus } \\
\text { of inquiry? }\end{array}$} \\
\hline $\begin{array}{l}\text { 2. Discovery } \\
\text { "What gives life?" }\end{array}$ & $\begin{array}{l}\text { Discover and } \\
\text { appreciate personal } \\
\text { and organizational } \\
\text { "high point" stories } \\
\text { and experiences. }\end{array}$ & $\begin{array}{l}\text { Gathering stories and } \\
\text { key ideas that identify } \\
\text { the organization's } \\
\text { "positive core." }\end{array}$ & $\begin{array}{l}\text { Stories as evidence of } \\
\text { values and best } \\
\text { practices; greater sense } \\
\text { of openness and } \\
\text { listening skills, builds } \\
\text { trust, generates } \\
\text { positive energy. }\end{array}$ \\
\hline $\begin{array}{l}\text { 3. Dream } \\
\text { "What might be?" }\end{array}$ & $\begin{array}{l}\text { Co-create a desired } \\
\text { future from } \\
\text { collective, } \\
\text { imaginative and } \\
\text { innovative capacity } \\
\text { of the group. }\end{array}$ & $\begin{array}{l}\text { Co-create visions of all } \\
\text { the elements participants } \\
\text { want to introduce into } \\
\text { communities or } \\
\text { workplaces. }\end{array}$ & $\begin{array}{l}\text { Clear statements and } \\
\text { images of members } \\
\text { "idealized" } \\
\text { organization; increased } \\
\text { creativity; amplifies } \\
\text { voices of hope. }\end{array}$ \\
\hline $\begin{array}{l}\text { 4. Design } \\
\text { "How can it be?" }\end{array}$ & $\begin{array}{l}\text { Choose the design } \\
\text { elements that will } \\
\text { support and develop } \\
\text { the organization } \\
\text { structures to bring the } \\
\text { dream to life. }\end{array}$ & $\begin{array}{l}\text { Participants identify } \\
\text { which projects they want } \\
\text { to be a part of to make } \\
\text { the dream happen. }\end{array}$ & $\begin{array}{l}\text { Begin to submit basic } \\
\text { project plans for } \\
\text { consideration and } \\
\text { refinement; begin to } \\
\text { see shifts in behavior } \\
\text { and mindset; increased } \\
\text { empowerment. }\end{array}$ \\
\hline $\begin{array}{l}\text { 5. Destiny/ } \\
\text { Deliver } \\
\text { "What will be?" }\end{array}$ & $\begin{array}{l}\text { Sustain momentum in } \\
\text { organization; build } \\
\text { capacity of } \\
\text { participants to } \\
\text { continue the process } \\
\text { themselves. }\end{array}$ & $\begin{array}{l}\text { Continued learning and } \\
\text { adapting, consider new } \\
\text { iterations of the cycle, } \\
\text { engage in possibility } \\
\text { thinking and looking for } \\
\text { "opportunities" vs. } \\
\text { problems. }\end{array}$ & $\begin{array}{l}\text { Participants become } \\
\text { "appreciative leaders" } \\
\text { who champion self- } \\
\text { sustaining change; } \\
\text { cultural shift towards } \\
\text { strength-based } \\
\text { appreciative practices. }\end{array}$ \\
\hline
\end{tabular}

See Cooperrider et al., 2008; Donnan, 2005; Stratton-Berkessel, 2010, p. 33-34.

Busche and Kassam (2005) suggested that Ai's transformative potential comes from focusing on changing how people think rather than what they do. Rather than emphasizing action-plans, Ai supports self-organizing change processes that flow from new ideas (Busche \& Kassam). The outcomes that distinguish Ai from other organizational development interventions are that Ai results in new knowledge, models, and theories that are co-constructed by participants. Appreciative inquiry results in a generative metaphor; that is, provocative statements that create new possibilities and compel new action (Busche \& Kassam). 
Schall et al. (2004) argued that appreciative inquiry can help us more effectively understand leadership. "Given the roots of appreciative inquiry in constructionism, and an emerging trend to see leadership as a social construct, appreciative inquiry emerges as one of the most appropriate methodological frameworks to pursue empirical work on leadership" (p. 148). Modern conceptions of leadership emphasize relational perspectives and the process of leaders and followers working together to create positive change (Drath, 2001; Komives, Lucas, \& McMahon, 2005; Rost, 1993). Fairhurst and Grant (2010) described the convergence of social constructionism and leadership, resulting in an approach that places increased emphasis on the ability of both leader and follower to co-constructed reality through the processes and outcomes of social practices. Drath \& Palus (1994) proposed that leadership is primarily a meaningmaking process within social communities. They note that meaning-making happens when "members develop psychologically" (p. 22), when "new forms of practice are created" (p. 22), and as structures evolve which provide "new ways of bringing the community into relationship with one another" (p. 22) and the world. From a relational perspective, leadership is not merely a possession of a leader, but an aspect of the community or organization. It is a communal capacity and achievement (Drath, 2001). Of interest is the question, "How do people working together in teams, organizations, and communities bring leadership into being?" (Drath, p. xvi).

After studying a variety of leadership education programs, Eich (2008) found that high quality leadership programs engage in "research-grounded continuous program development" (p. 184). In particular, the use of a systems-thinking approach allows programs to act on research about learning, program development, and leaders. Eich indicates this happens when (a) program development utilizes current leadership and learning models and (b) practitioners and students engage in program improvement together using a variety of assessment and feedback tools. Further, Eich notes that these actions help students and faculty gain a scholarly, research-grounded perspective that they can apply in their own practice.

Middlebrooks and Allen (2008) emphasized the need to help students make connections between models and theories of leadership and the activity and practice of leadership. As leadership programs employ the Ai model, they create moments of learning for administrators, faculty, staff, and students. There is an opportunity to not only learn about the theory involved, but to also experience the theory in practice. Throughout the Ai process, educators and students are generating new theories and knowledge to guide new practices within their own communities. This bridge between theory and practice influences the development of identities as department, program, or project members. As Eich (2008) explained, "Students' self-concept and leadership identity development is advanced through program alignment with the students' development and program standards to uphold" (p. 184). The change is not just programmatic, it 
involves the transformation of identities of all who are involved. Appreciative inquiry is not just about changing structures, but constructing new patterns of thinking that promote adaptability in our response to complex challenges.

\section{Description of Practice}

The leadership education faculty at Virginia Tech has been utilizing Ai in ongoing strategic planning and organizational development projects at three levels. The following case examples overview the context and goal of each strategic planning project and describe how facilitators and participants engaged in the $\mathrm{Ai}$ process.

\section{Organizational and Department Strategic Planning}

During the 2011-2012 academic year two different academic departments at Virginia Tech approached the authors of this paper for guidance on facilitating departmental retreats. Both had recently completed formal departmental reviews and were considering where to focus their efforts to move forward. The retreats were scheduled to include both faculty and staff and there was a conscious desire to approach the retreat in a way that would improve the sense of community in the department. Perceived boundaries between faculty and staff members can sometimes inhibit communication, so the approach needed to include an increased emphasis on open communication. The World Café Method was identified as a potential tool for promoting and facilitating open communication. World Café is an educational strategy that facilitates collaboration and shared meaning-making through interactive dialogue. The use of powerful questions focuses inquiry, surfaces assumptions and biases, and opens up new possibilities for ideas and meaning (Brown et al., 2005). According to World Café Community Foundation (n.d.), World Café can take a variety of forms, but generally includes the following components:

- Setting: Creating a hospitable place, usually cafe style round tables with at least four chairs at each table. Flipcharts or butcher block paper and markers are set at each table, with the invitation to doodle, draw, and create.

- Welcome and Introduction: The facilitator or host opens with a welcome and introduces the World Cafe process and in this case, also the $\mathrm{Ai}$ process. Setting the context gives purpose that helps focus both the content and provides support to the process of the dialogue (Brown et al., 2005).

- Small Group Rounds: Conversation takes at each table during multiple timed rounds (i.e., 10-20 minutes each, depending on the context and purpose). At the end of each round, group members will move to different tables, creating a cross pollination effect as participants develop new connections and relationships (Brown et al., 2005). Usually one person stays at the table as a host for the next round by welcoming the new group and providing a brief recap of the previous round. 
- Questions: A signature aspect of the World Cafe is an exploration of "questions that matter" (Brown et al., 2005. p. 78). Each round of dialogue is prefaced with a question or series of questions designed for the specific context and desired purpose of the session. This of particular importance in $\mathrm{Ai}$, as the questions set the stage for what is discovered. A single question may be used for more than one round or questions can be sequenced to provide a guide for discussion.

- Harvest: At various intervals, usually after the small group rounds, individuals are invited to share insights or other results from their conversations with the rest of the large group. The emerging collective understanding is often captured graphically and textually on flip charts at the front of the room. (World Café Community Foundation, n.d.)

In the design stage the facilitator and key administrative faculty identified the affirmative topic as defining signature work for growth and distinction within their respective departments. The World Café Method was used to facilitate both the discovery and dream stages of Ai during the department retreats. The discovery stage was guided by the following prompts:

- Best Experience: Share about the best times that you have had with the department. Looking at your entire experience, recall a time when you felt most alive, most involved, or most excited about your involvement. What made it an exciting experience? What helped to make it possible? Describe the event in detail.

- Interpretation: What is it about this department - its structure, systems, processes, policies, staff, leaders, strategy - that create conditions where success can flourish?

The dream stage was guided by the following prompts:

- Achievements: It is 2016, and you are preparing for the next [external] review. What are you highlighting as the department's achievements?

- Wishes: If you had three wishes for the department, what would they be?

Both stages were completed during morning sessions totaling less than three hours. The retreats continued with afternoon sessions focused on the design stage of Ai, guided by an action planning worksheet to generate a list of desired results, actions needed, resources needed, and target date for completion. Participants volunteered to serve in smaller work groups to set goals and design vision-based strategies to guide departmental practices.

\section{Program Level Strategic Planning}

In spring 2011, four undergraduate honors students conducted an informal program assessment of a Leadership Living-Learning Community program at Virginia Tech utilizing the Council for the Advancement of Standards (CAS) selfstudy for Student Leadership Programs (CAS, 2009). The finding they reported 
implied that the mission, values, and learning objectives of the community were not clearly stated and did not fully express students' experience in the program, and did not encompass the overall impact on their leadership development. The learning community has had three director transitions over the past four years. There was general confusion among stakeholders over what the program was and was for. The interim director and undergraduate academic coordinator initiated a strategic visioning process to reconsider the mission statement, create a vision statement, and identify core values and learning outcomes to guide the program into its next stage of life. The Ai approach seemed most appropriate to be able to encompass and honor historical perspectives while encouraging the generation of new possibilities that express and expand the program's value within the Virginia Tech campus and the Department of Agriculture and Extension Education.

A faculty member who was not directly involved in the program served as the facilitator so that the program's leaders could engage as full participants in the dialogue. However, the design stage was initiated by the interim director, residential director, academic coordinator, and faculty facilitator. Through several meetings they determined the focus of the inquiry would be - the future of the Residential Leadership Community (RLC). The first two-hour visioning session held in spring 2012 also utilized a World Café format and focused on the dream and discovery stages. A total of 20 individuals from multiple stakeholder groups participated including university alumni, faculty/instructors, administrators, residence life staff, current students, and program student leaders. The discovery stage began by discussing, "What gives our community life?" The following questions served as a discussion guide:

- What were your best experiences related to each of our core areas?

- What do we do well in each of our core areas? What works?

- What do you value most about each of these core areas? Why are they important components of the program?

Transitioning into the dream stage, participants envisioned, "What might be?" The following questions guided discussion:

- What are our hope and aspirations for students who participate in the Residential Leadership Community?

- What does full engagement in each of these areas look like?

- What other elements could add to/enhance the RLC experience?

Data was captured through observations and by participants during each World Café round on flip charts and later summarized into a written document. A smaller group of volunteers including some of the initial group, as well as other key program stakeholders, were recruited to form a work group to review the data and begin the next stage (i.e., design). The goal of this stage was to craft a vision statement, goals, and learning objectives to guide the program for the next three to five years. 


\section{Project Level Planning}

A signature component of an introductory freshman-level leadership course at Virginia Tech is focused on student-led service experiences. During the fall 2011 semester students worked in small groups to identify a campus or community organization with whom they could partner for at least four hours of direct service. While students found this to be an overall valuable experience, feedback showed that that the process itself was confusing and at times frustrating for students, peer leaders such as teaching assistants, and faculty. The director desired to do a more in-depth assessment of the experience to create recommendations for revisions. She recruited two peer leaders (i.e., sophomores) and an intern (i.e., junior) who had been part of the service project experience to lead an Ai process. The peer leaders would receive honors credit thorough their participation.

The team decided that focus groups would be the most effective method of inquiry because they are more efficient than individual interviews and create a social context for dialogue and interaction. They could also tailor questions specifically toward each specific group identified as students, faculty, peer leaders, and program staff. The director and the students met several times to discuss the objectives and review concepts of Ai. They worked through the design stage together, identifying the guiding topic of inquiry as, "The successful integration of service learning in [leadership class]." A basic focus group protocol was scripted to engage participants in a combined dream and discovery stage. They followed a prescribed flow of questions which included (a) opening questions to set the tone and energy, (b) topical questions related to the affirmative statement, and (c) closing questions focused on a positive future vision (Cooperrider et al., 2008). Some examples of these topics included:

- Opening: What do you value or appreciate most about the opportunity to learn leadership as part of this program?

- Topical: Please share a story of something that went really well (i.e., a high-point) during the project planning or event that made you feel really alive, challenged, or effective.

- Closing: It is a year from today and you are talking to the new freshman class about their project experiences. What do you hope they tell you about the experience?

\section{Experiences and Lessons}

An important consideration of $\mathrm{Ai}$ is that it is an on-going process. These Ai cases were initiated over a six-month period and long-term results may not be fully realized for quite some time. However, we are able to discuss the experiences and preliminary outcomes of the initial stages of the process. 
In each example, the design stage was initiated by the facilitator and key administrative leaders. We found this to be most efficient and useful in recruiting participants because we could clearly articulate the topic of the discussion. Rather than taking up retreat and meeting time determining the focus of inquiry, we were able to spend more time explaining the philosophy setting context and clarifying the higher purpose behind the Ai process.

In all of our examples we found that the discovery and dream stages paired well. There are a variety of methods that can be used to gather stories and envision the future; however, we feel that the World Café and focus groups were effective strategies to include a lot of people in a relatively short amount of time. As a result of creating contexts in which participants were given a voice in the visioning process, we were able to generate a greater sense of connection, openness, and trust in the various groups.

The program and project level inquiries are just now entering the design stage; however, the departmental level Ai process is now well into this stage. After one departmental retreat the participants followed up on the creation of targeted goals with weekly lunch-and-learn style work group meetings to encourage continuous collaboration. This simple act of weekly meetings is an example of changed behavior as a result of the Ai process. The potential for long-term success is due to the fact that this was participant-initiated, not an administrative mandate. As participants are empowered to create and carry on the work of the organization with a strengths-oriented perspective and Ai practice, they themselves become appreciative leaders (Schiller, Holland, \& Riley, 2001).

\section{Recommendations and Implications}

Whitney, Trosten-Bloom, and Radan (2010) define the term "appreciative leadership [as] the relational capacity to mobilize creative potential and turn it into positive power...to make a difference in the world" (p. 3). Appreciative inquiry provides a useful solution for organizations that desire to break out of the problem-oriented mindset and embrace a strengths-based philosophy. The value of Ai lies in its philosophy and practice. We believe leadership educators are uniquely positioned to bridge theory and practice through the use of Ai models, influencing our ability to effectively train and develop students and also influence positive change in our organizations. From these case examples, we offer the following implications:

- Because Ai pushes against the grain of traditional problem-solving approaches that dominate organizational development, practitioners may encounter resistance to the approach. For example, participants may be eager to skip over early stages to get to the solutions. Educating participants on the philosophy and value of the process is important in changing mindsets and creating openness in dialogue which is necessary for the co-construction of new possibilities. 
- While an outside facilitator may be a helpful resource for the initial stages of the Ai cycle, it really becomes the job of the leader to sustain positive change. Appreciative inquiry may itself be considered a transformational process because it promotes changes in how people think and what they do (Bushe \& Kassam, 2005). Within leadership education, Ai could be a force for transformational leadership development. For example, as participants engage together in the work of leadership in dealing with change, they may develop higher levels of motivation and performance.

- Through Ai, we can gain insight into the social construction of leadership, in particular how groups make-meaning of their experiences in social communities and enact change practices. Appreciative inquiry is poised to emerge as an important methodology for leadership research (Schall et al., 2004).

- There is the potential to explore Ai as an identity formation process. As Ai shapes organizational identity, participants' sense of self, belonging, and view of their role within the organization is also shaped through the construction and alignment of the shared vision, goals, and standards. In the process of constructing what could be the participants are also becoming leaders who are able to enact that preferred future. 


\section{References}

Androetti, V. (2010). Post colonial and post-critical "global citizen educator". In G.Elliot \& S. Isslar (Eds.), Education and social change: Connecting local and global perspectives (239-250). New York: Continuum Publishing Group.

Ayman, R., Adams, S., Fisher, B., \& Hartman, E. (2003). Leadership development in higher education institutions: A present and future perspective. In S. E. Murphy \& R. E. Riggioso (Eds.), The future of leadership development [Electronic book] (201-222). Mahwah, NJ: Lawrence Earlbaum.

Brown, J., \& Isaacs, D., \& Associates (2005). The world cafe: Shaping our futures through conversations that matter. San Francisco: BerrettKoehler Publishers.

Bushe, G. R., \& Kassam, A. F. (2005). When is appreciative inquiry transformational? A meta-analysis. The Journal of Applied Behavioral Science, 41(2), 161-181.

Cooperrider, D. L., \& Srivasta, S. (1987). Appreciative inquiry in organizational life. Research in Organizational Change and Development, 1, 129-169.

Cooperrrider, D. L., Whitney, D., \& Stavros, J.M. (2008). Appreciative inquiry handbook: For leaders of change (2nd ed.). San Francisco: BerrettKoehler Publishers.

Council for the Advancement of Standards in Higher Education (2009). CAS professional standards for higher education ( $7^{\text {th }}$ ed.). Washington, DC: Author.

Donnan, S. (2005). What is appreciative inquiry? Metavolution Website. Retrieved from http://www.metavolution.com/rsrc/articles/whatis_.htm

Drath, W. H. (2001). The deep blue sea: Rethinking the source of leadership. San Francisco: Jossey-Bass.

Drath, W. H., \& Palus, C. J. (1994). Making common sense: Leadership as meaning-making in a community of practice. Greensboro, NC: Center for Creative Leadership.

Eich, D. (2008). A grounded theory of high quality leadership programs: Perspectives from student leadership development programs in higher education. Journal of Leadership \& Organizational Studies, 15(2), 176187. DOI: $10.1177 / 1548051808324099$ 
Fairhurst, G. T., \& Grant, D. (2010). The social construction of leadership: A sailing guide. Management Communication Quarterly, 24(2), 171-210.

Heifetz, R., Grashow, A., \& Linsky, M. (2009). The practice of adaptive leadership: Tools and tactics for changing your organization and your world. Boston: Harvard Business Press.

Higher Education Research Institute (1996). A social change model of development (Vol. III). Los Angeles: University of California Los Angeles Higher Education Research Institute.

Klein, R. H, Rice, C. A., \& Schermer, V. L. (2009). Introduction: Co-creating indepth leadership for a new millennium. In R. Klein, C. Rice, \& V. Schermer (Eds.), Leadership in a changing world: Dynamic perspectives on groups and their leaders (1-25). Lanham, MD: Lexington Books.

Komives, S. R., Lucas, N., \& McMahon, T. R. (2007). Exploring leadership: For college students who want to make a difference $\left(2^{\text {nd }}\right.$ ed.). San Francisco: Jossey-Bass.

Kotter, J. P. (1996). Leading Change. Harvard Business Review Press: Boston.

Middlebrooks, A., \& Allen, S. J. (2008). Leadership education: New challenges, continuing issues. International Leadership Journal, 1(1), 77-85.

Pink, D. H. (2006). A whole new mind. New York: Penguin Books.

Rost, J. C. (1993). Leadership for the twenty-first century. Westport, CT: Praeger.

Schall, E., Ospina, S., Godsoe, B., \& Dodge, J. (2004). Appreciative narratives as leadership research: Matching method to lens. In D. L. Cooperrrider \& M. Avital (Eds.), Constructive discourse and human organization (147170). Oxford, UK: Elsevier Ltd.

Schiller, M., Holland, B. M., \& Riley, D. (Eds.) (2002). Appreciative leaders: In the eye of the Beholder (2nd ed.). Chagrin Falls, OH: Taos Institute.

Stratton-Berkessel, R. (2010). Appreciative inquiry for collaborative solutions: 21 strength-based workshops. San Francisco: Pfeiffer.

Wheatley, M. J. (2009). Turning to one another: Simple conversations to restore hope to the future ( $2^{\text {nd }}$ ed.). San Francisco: Barrett-Koehler. 
Whitney, D., Trosten-Bloom, A., \& Rader, K. (2010). Appreciative leadership: Focus on what works to drive winning performance and build a thriving organization. New York: McGraw-Hill.

World Café Community Foundation (n.d.). World café method. Retrieved from: http://www.theworldcafe.com/method.html 


\section{Author Biographies}

Kerry L. Priest is an assistant professor in the School of Leadership Studies at Kansas State University. Her research interests address student leadership development and identity formation within communities of practice.

Eric K. Kaufman is an assistant professor in the Department of Agricultural and Extension Education at Virginia Tech. He has also been involved in developing leadership programming for adult and youth organizations. Eric's research interests include multiple aspects of leadership and leadership development, including agricultural, collegiate, grassroots, strengths-based, and volunteer leadership.

Kelsey Brunton is pursuing a master's degree with a focus in leadership and organizational development in the department of Agricultural Extension and Education at Virginia Tech. Her research investigates two methods of organizational development, SWOT analysis, and Appreciative Inquiry to compare participants' perception of vision clarity and participant buy-in of a shared vision.

Megan Seibel is the Director of the Virginia Agriculture Leaders Obtaining Results (VALOR) program. This program focuses on developing leaders who can effectively engage all segments of the Virginia agricultural community to create collaborative solutions and promote agriculture inside and outside of the industry. She holds a doctorate in Agricultural and Extension Education from Virginia Tech. 